Article

\title{
Laser Texturing for Superwetting Titanium Alloy and Investigation of Its Erosion Resistance
}

\author{
Zhiguo Wang ${ }^{1,2, * \mathbb{D}}$, Jinpeng Song ${ }^{1,2}$, Tianyi Wang ${ }^{3}$, Huixin Wang ${ }^{4}(\mathbb{D}$ and Qinghua Wang $5,6, * \mathbb{C}$ \\ 1 School of Mechanical Engineering, X' $i^{\prime}$ an Shiyou University, Xi'an 710065, China; sjp18729288070@163.com \\ 2 Xi'an Key Laboratory of Wellbore Integrity Evaluation, Xi'an 710065, China \\ 3 Research Institute of Petroleum Exploration \& Development, PetroChina, Beijing 100083, China; \\ wangtianyi69@petrochina.com.cn \\ 4 Institute of Agricultural Facilities and Equipment, Jiangsu Academy of Agricultural Sciences, \\ Nanjing 210014, China; wanghx17@mails.jlu.edu.cn \\ 5 School of Mechanical Engineering, Southeast University, Nanjing 211189, China \\ 6 Jiangsu Key Laboratory for Design and Manufacture of Micro-Nano Biomedical Instruments, \\ Nanjing 211189, China \\ * Correspondence: wangzhiguo029@hotmail.com (Z.W.); qinghua-wang@seu.edu.cn (Q.W.)
}

check for updates

Citation: Wang, Z.; Song, J.; Wang, T.; Wang, H.; Wang, Q. Laser Texturing for Superwetting Titanium Alloy and Investigation of Its Erosion Resistance. Coatings 2021, 11, 1547. https:// doi.org/10.3390/coatings11121547

Academic Editor: Alexander D. Modestov

Received: 10 November 2021 Accepted: 13 December 2021 Published: 16 December 2021

Publisher's Note: MDPI stays neutral with regard to jurisdictional claims in published maps and institutional affiliations.

Copyright: (c) 2021 by the authors. Licensee MDPI, Basel, Switzerland. This article is an open access article distributed under the terms and conditions of the Creative Commons Attribution (CC BY) license (https:// creativecommons.org/licenses/by/ $4.0 /)$.

\begin{abstract}
Erosion of materials is one of the major causes that lead to the malfunction of equipment and facilities, and surface texturing can be a solution for enhancement of erosion resistance. In this work, superwetting (superhydrophilic/superhydrophobic) titanium (Ti) alloy surface with periodic microstructure was prepared by a facile laser-based surface texturing approach which combines laser surface texturing and low-temperature annealing. The effect of laser-induced surface texture and wettability on the erosion resistance of the laser textured surface was studied. Scanning electron microscopy (SEM) and energy dispersive spectroscopy (EDS) were used to analyze the chemical surface microstructure and surface on the untreated and laser textured surfaces. The hardness and contact angle of the untreated surface, superhydrophilic surface and superhydrophobic surface were measured by microhardness tester and contact angle goniometer. Using an in-house built erosion experimental setup, the erosion resistance of the untreated surface, superhydrophilic surface and superhydrophobic surface was investigated. The experimental results demonstrate that micro-bumps are formed after laser surface texturing. In the meantime, the surface hardness for the laser textured surface with a step size of $150 \mu \mathrm{m}$ is increased by $48 \%$ under the load of $1.961 \mathrm{~N}$. Compared with the untreated surface, the erosion resistance is increased by $33.9 \%, 23.8 \%$ and $16.1 \%$, respectively, for the superhydrophobic surface. The SEM results show that the untreated surface has large and deep impact pits, while the superhydrophobic surface only has small and shallow impact pits, indicating that the erosion process resulted in less damage to the substrate. The EDS results shows that superhydrophobicity plays a critical role in protecting the substrate from erosion. It is thus believed that the superhydrophobic surface has pronounced effects for improving the hardness and erosion resistance of $\mathrm{Ti}$ alloy.
\end{abstract}

Keywords: titanium alloy; laser texturing; superwetting; erosion resistance

\section{Introduction}

Titanium (Ti) alloy has some distinct advantages of high melting point, low density, high specific strength, high fatigue strength, good thermal resistance and biocompability, low thermal expansion coefficient and elastic modulus. Compared with the light metal and modern high-strength steel, Ti alloy appears to be a lightweight structural material with high reliability [1-3]. Ti alloy has been widely applied in aerospace, energy, marine engineering, defense and biomedicine [4]. However, its low hardness and poor abrasion resistance have limited the wider applications of the Ti alloy [3,5-8]. In petroleum and marine industries, corrosive wear induced by the erosion of materials is one of the major 
causes that lead to the malfunction of equipment and facilities, including oil tube, hydroturbine, pump and tubes used for transportation of solid particle. In this case, solid particle will combine with liquid forming liquid-solid two-phase flow and affect the component surface, leading to localized damage. Therefore, the working efficiency can be significantly reduced, and the production cost will increase. As some components would malfunction at a very early stage, safety issues will also be inevitable [9].

Surface properties of materials, including hardness, plasticity and toughness, will typically have pronounced effects on the erosion resistance. For the relationship between hardness and erosion rate, it is generally believed that the erosion rate of plastic materials is maximized and close to being saturated when the harness ratio between the erosion particles and material surface is higher than 1.2. When the ratio is lower than 1.2, the erosion rate will decrease as the ratio decreases [10]. The erosion mechanism of brittle materials and ductile materials is different, resulting in different erosion rates at different impact angles. At high impact angles, the brittle materials can produce cracks and result in higher erosion rate than ductile materials; on the contrary, at low impact angles, ductile materials are prone to produce a plasticity deformation and higher erosion rate than brittle materials.

As surface properties play a key role for enhancing the erosion resistance of materials, modification of surface functionalities is essentially needed to better achieve the target. In recent years, surface texturing has been widely utilized to modify the surface properties of various materials (including metals, polymers and glass) and elevate surface functions, thus obtained textured surface with improved erosion/corrosion resistance [11-16]. For example, by texturing the titanium (Ti) alloy surface, some key surface properties, including wettability and hardness, can be effectively modified and controlled, indicating the superior advantage of surface texturing techniques [17-19]. So far, many surface texturing techniques have been developed and utilized by academia and industries [20], and the most widely used techniques include Vibrorolling technique [21,22], UV-LIGA technique [23], deep reactive ion etching [24-26], surface peening [27] and laser surface texturing [28-37]. Among these surface texturing techniques, laser surface texturing has received considerable attention due to some distinct advantages such as flexibility, high precision, low cost, high processing efficiency and ease for industrial automation [38]. Therefore, laser surface texturing is considered as one of the most efficient and promising material processing technique.

The general purpose of surface texturing is to modify and control surface properties, and a key one of these properties is surface wettability. Achieving extreme surface wettability scenarios, including superhydrophobicity and superhydrophilicity, has great significance for various industrial and biomedical applications [39]. There are two main methods for fabrication of surfaces with extreme wettabilities: one method is by depositing hydrophilic or hydrophobic coatings onto the substrate, which includes crystal growth $[40,41]$ and electrochemical processing [42], and the other method directly creates microstructures on the substrate, which includes photolithography [43], micromachining [44], laser surface texturing [45,46] and so forth [47].

As manifested by various researchers, surfaces with extreme wettabilities, especially those with a superhydrophobic surface, can effectively enhance the erosion resistance of materials [48-50]. Thus, in the past few decades, laser surface texturing has also been utilized for fabrication of erosion-resistant surfaces. AA Siddiquie et al. [51] prepared an $\mathrm{Al}_{\mathrm{x}} \mathrm{Cu}_{0.5} \mathrm{FeNiTi}$ high-entropy alloy coating by premixed high-purity mixed $\mathrm{Cu}, \mathrm{Fe}, \mathrm{Ni}$ and Ti powders on top of the AA 1050 substrate using laser surface alloying, in order to improve the microhardness and erosion resistance. The erosion behavior of the $\mathrm{Al}_{\mathrm{x}} \mathrm{Cu}_{0.5} \mathrm{FeNiTi}$ coating was evaluated using an air jet erosion experimental setup. The experimental results indicate that the microhardness of the $\mathrm{Al}_{\mathrm{x}} \mathrm{Cu}_{0.5} \mathrm{FeNiTi}$ high-entropy alloy coating is 17 times higher than that of the AA1050 aluminium substrate, and the erosion resistance is also significantly improved using the coating. Wahab and Ghazali [52] fabricated microgrooves on the surface of a plasma sprayed alumina- $13 \%$ titania $\left(\mathrm{Al}_{2} \mathrm{O}_{3}-13 \% \mathrm{TiO}_{2}\right)$ coating using laser surface texturing. Several key surface properties, including hardness, phase composition 
and erosion wear resistance, were studied and compared with the non-textured coating. Through slurry pot erosion test at different impact angles and microstructural analysis using scanning electron microscope, it is concluded that the cumulative mass loss can be effectively reduced and the erosion resistance is distinctly enhanced on the laser surface textured coating surface. Yu et al. [53] obtained amorphous Fe base alloy coating using laser melting and found that a denser coating can be formulated using the laser remelting process, which can better resist the impact of $90^{\circ}$. Wu et al. [54] textured the Ti alloy using laser etching and raised the contact angle of the surface from $60.2^{\circ}$ to $114.6^{\circ}$, indicating the laser etched surface became hydrophobic. The erosion test was conducted on both the laser-induced hydrophobic surface and the untreated surface. The experimental results show that the erosion rate of the laser etched surface is only a little higher than that of the untreated surface. This indicates the laser etching method can well retain the erosion resistance while enhance the anti-icing performance of Ti alloy.

The above-mentioned research efforts demonstrate that the laser-induced microtextured surface can effectively enhance the corrosion resistance, thus plays a key role for applications of anti-friction and anti-erosion. This is mainly attributed to the existence of surface texture which could efficiently prevent the diffusion of cracks to the adjacent area. However, note that the investigation of erosion performance in liquid-solid two-phase flow for the laser textured superwetting Ti surface is still lacking.

In this work, a UV nanosecond laser is firstly utilized to prepare micro-texture on Ti-6Al-4V alloy, and a heat treatment of $150^{\circ}$ is subsequently conducted to convert the surface wettability from superhydrophilicity to superhydrophobicity. The laser-induced surface texture is examined using scanning electron microscopy, and the wettability and surface chemistry are analyzed using contact angle goniometer and energy-dispersive $\mathrm{X}$-ray spectroscopy, respectively. The erosion tests are conducted using an in-house built erosion experimental setup and the liquid-solid two-phase flow liquid mixed with silica sand particles and DI water is used as the testing solution. The erosion performance for the laser textured surfaces with different step sizes and wettability is evaluated and compared with that of the untreated surface, in order to investigate the effect of laser processing parameters and surface wettability on the erosion resistance of Ti alloy.

\section{Materials \& Methods}

\subsection{Materials}

Commercially available Ti-6Al-4V sheets are used as the test samples, which have been machined with a dimension of $50 \mathrm{~mm} \times 50 \mathrm{~mm} \times 2 \mathrm{~mm}$. The samples are cleaned successively with acetone, ethanol and deionized (DI) water in order to remove the contaminants.

\subsection{Laser Texturing Experiments}

Laser surface texturing experiments utilize a laser marking machine (TH-UV200A, Tianhong Laser, Suzhou, China) which is equipped with a UV laser source of $355 \mathrm{~nm}$ (AWAVE 355-15W-30K, Advanced Optowave, Ronkonkoma, NY, USA). The laser beam is guided by a set of pre-aligned reflective mirrors and directed into the scan head configured with an f-theta objective. The laser power intensity and laser beam diameter are controlled by the attenuator and beam expander, respectively. The focusing lens of the scan head ensures that the focal spot diameter during the laser texturing experiments is $\sim 40 \mu \mathrm{m}$. During the laser texturing process, an area of $30 \mathrm{~mm} \times 30 \mathrm{~mm}$ is textured using unidirectional line profiles, and the step sizes (distance between each two-line scans are set as 150,200, 250 and $300 \mu \mathrm{m}$, as schematically illustrated in Figure 1). The detailed laser processing parameters used in this work can be found in Table 1. 


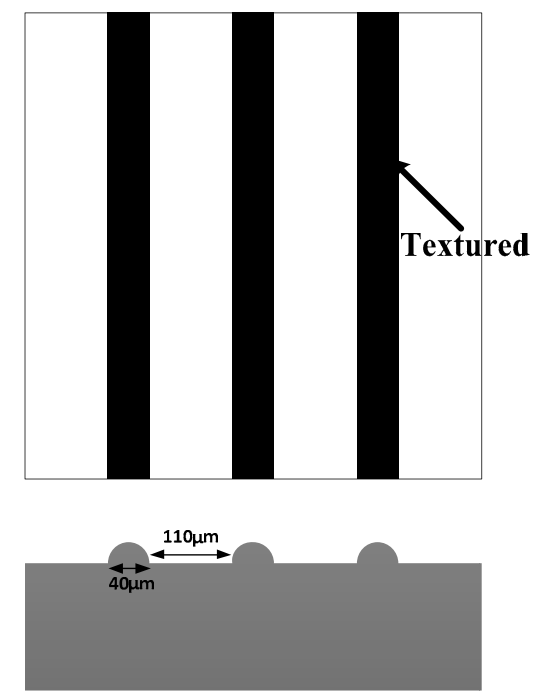

Figure 1. Schematic diagram of the cross-sectional area of the laser textured surface.

Table 1. Laser processing parameters used in this work.

\begin{tabular}{cc}
\hline Parameter & Value \\
\hline Wavelength $(\mathrm{nm})$ & 355 \\
Average power $(\mathrm{W})$ & 14.7 \\
Repetition rate $(\mathrm{kHz})$ & 30 \\
Pulse width $(\mathrm{ns})$ & 20 \\
Scanning speed $(\mathrm{mm} / \mathrm{s})$ & 40,70 \\
Step size $(\mu \mathrm{m})$ & $150,200,250,300$ \\
Power intensity $\left(\mathrm{GW} / \mathrm{cm}^{2}\right)$ & 1.95 \\
Pulse energy $(\mathrm{mJ})$ & 0.5 \\
\hline
\end{tabular}

Immediately after laser surface texturing, the Ti-6Al-4V surface will enter a saturated Wenzel regime after being textured in the ambient air, thus exhibiting superhydrophilicity. To achieve the conversion from superhydrophilicity to superhydrophobicity, a conventional oven is utilized to thermally treat the laser textured surface with an annealing temperature of $150{ }^{\circ} \mathrm{C}$. The whole heat treatment process lasts for two hours.

\subsection{Surface Characterizations}

To determine and analyze the laser-induced periodic surface structures and the chemical compositions on the surface, a scanning electron microscope equipped with an energydispersive X-ray spectroscopy (EDS) detector (JSM-6390A, Japan Electronics Co. Ltd., Tokyo, Japan) is utilized. The water contact angle is measured using a contact angle goniometer (SDC-200, Sindin Precision Instrument Co. Ltd., Dongguan, China), and multiple contact angle measurements are performed on four different locations of the surface and the average value is reported. The surface microhardness is experimentally measured using a Vickers microhardness tester (HXD-1000TMC/LCD, Shanghai Qinming Optical Instrument Co. Ltd., Shanghai, China). The test load is set at $200 \mathrm{gf}$, and the dwell time is set as $15 \mathrm{~s}$. Five hardness measurements are taken at different locations on each test sample, and the average value is reported.

\subsection{Liquid-Solid Two-Phase Flow Erosion Tests}

The erosion tests are conducted using an in-house built erosion experimental setup, which can be found in Figure 2a. The liquid-solid two-phase flow liquid is prepared by mixing the silica sand particles with DI water, the mass ratio of sand is $1 \%$, and Figure $2 b$ demonstrates the irregular shape of the silica sand particles. The test sample is clamped on the holder, while the distance between the test sample and the nozzle is set as $14 \mathrm{~mm}$. 
The mixed fluid is then poured into the agitation tank, and the holder is put into the mixed fluid. Subsequently, the agitation tank is launched first. As the mixed fluid is stirred well, the centrifugal pump is launched as well. The fluid will eject from the nozzle and hit the test sample. After the flow rate is stabilized at $10 \mathrm{~m} / \mathrm{s}$, the actual erosion test will start. The whole erosion duration is set as $150 \mathrm{~min}$. For every $50 \mathrm{~min}$, the test sample will be released from the holder for weight measurement, and then put back until the end of the erosion test.

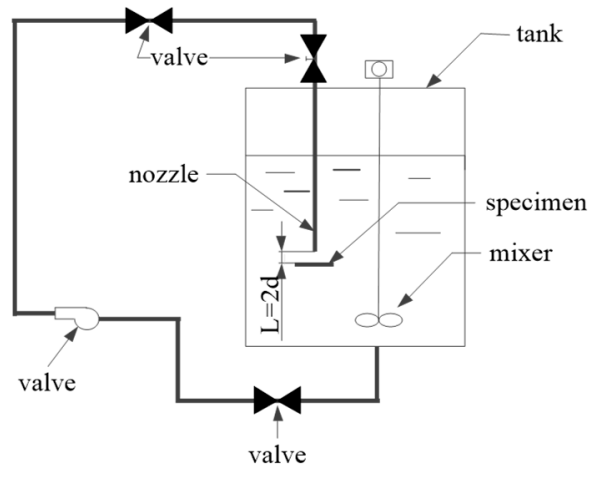

(a)

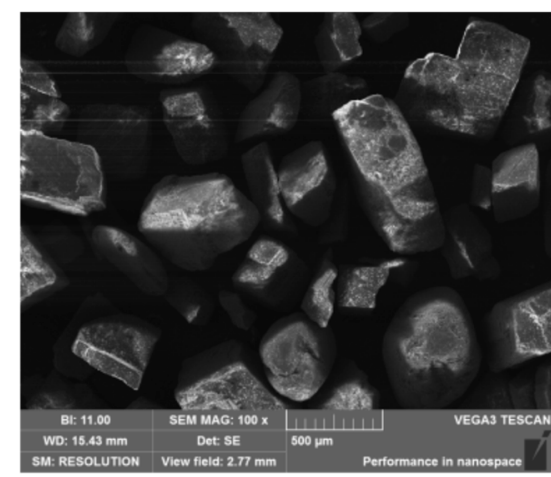

(b)

Figure 2. Schematic diagram of experimental device and micromorphology of sand used in the experiment. (a) Schematic diagram of experimental device (b) micromorphology of sand.

\section{Experimental Results}

3.1. Surface Morphology

The surface morphology of the untreated Ti surface and laser-textured Ti surfaces with different wettabilities are evaluated using SEM, as shown in Figure 3. The untreated Ti surface can be found in Figure $3 a$,b, with the magnifications of $500 \times$ and $1000 \times$, respectively. From Figure $3 a$, it can be observed that the untreated surface is relatively flat with a few scratches. From the figure with higher magnification (Figure 3b), it can be seen that there are some tiny particles on top of the untreated surface. The SEM images of the laser textured superhydrophilic surface using the step size of $150 \mu \mathrm{m}$ are shown in Figure $3 c, d$, with the magnifications of $500 \times$ and $2000 \times$, respectively. With the irradiation of laser beam, the surface is strongly ablated and evaporated [55], thus forming the micro-scale textures (micro-bumps in this work) on the surface. Some tiny particles, holes and cavities are also formed on top of the micro-bumps. The micro-bump formation is mainly attributed to the interaction effects between the recoil pressure and Marangoni flow [56]. The SEM images of the laser textured superhydrophobic surface using the step size of $150 \mu \mathrm{m}$ are shown in Figure $3 e, f$, with the magnifications of $500 \times$ and $2000 \times$, respectively. From Figure 3e,f, it can also be observed that laser surface texturing induces periodic micro-bumps along the scanned profiles, while irregular particles are ejected and deposited on top of the microbumps due to the strong interaction between the laser beam and the substrate. Overall, the sample of superhydrophobic surface has textured lines, which have been well defined in comparison with the sample of superhydrophilic surface.

\subsection{Surface Chemistry}

The surface chemistry of the untreated Ti surface and laser-textured Ti with different wettabilities is shown in Figure 4. It is demonstrated in Figure 4a that the elements of carbon $(\mathrm{C})$, aluminum $(\mathrm{Al})$ and $\mathrm{Ti}$ can be detected on the untreated surface. After laser texturing, the element of oxygen $(\mathrm{O})$ can be detected on the surface, as shown in Figure $4 \mathrm{~b}$,c. This indicates that the Ti surface has been oxidized during the laser texturing process. This is mainly attributed to the strong affinity between $\mathrm{O}$ and $\mathrm{Ti}$, thus rendering the formation of $\mathrm{TiO}_{2}$ with high hardness and a small amount of $\mathrm{Al}_{2} \mathrm{O}_{3}$, which can help to explain the high hardness of the laser textured Ti surface to be discussed in Section 3.4. The formation 
of oxides also leads to the reduction on the atomic percentage of $\mathrm{Ti}$ and $\mathrm{Al}$ on the laser textured surface $[20,57]$. It can also be found that the elemental composition of $C$ and $\mathrm{O}$ is relatively different in Figure $4 b, c$, which indicates that the surface chemistry of the laser-textured Ti with different wettabilities is also remarkably different.

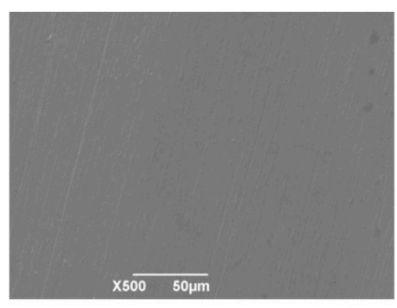

a

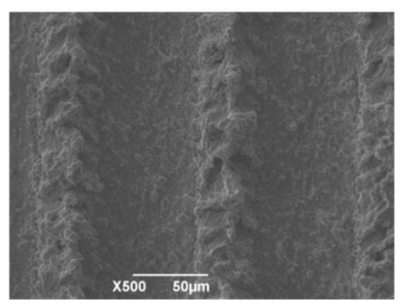

$\mathrm{c}$

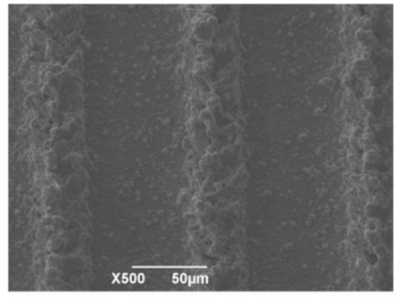

e

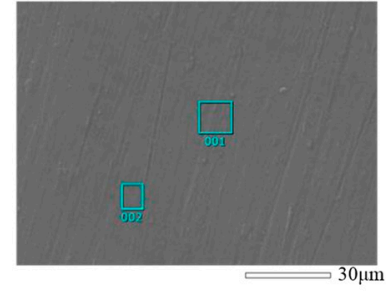

b

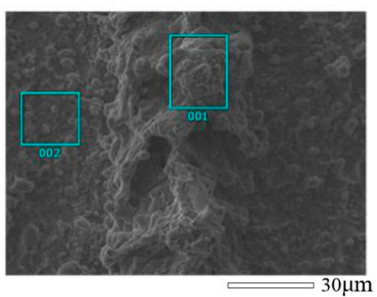

d

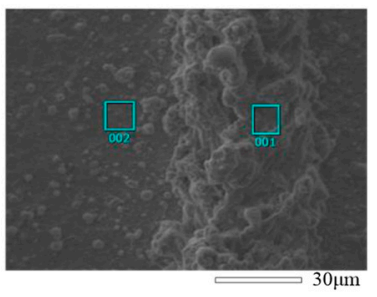

$\mathrm{f}$

Figure 3. SEM of the samples used in the experiment: $(\mathbf{a}, \mathbf{b})$ the untreated surfaces, $(\mathbf{c}, \mathbf{d})$ the superhydrophilic surface and $(\mathbf{e}, \mathbf{f})$ the superhydrophobic surface.

\subsection{Surface Wettability}

The surface wettability of the untreated Ti surface and laser textured Ti with different wettabilities is evaluated by static contact angle measurement, as shown in Figure 5. It is shown in Figure 5a that the untreated surface exhibits a contact angle of $64.8^{\circ} \pm 2.9^{\circ}$, meaning the surface is hydrophilic. Immediately upon laser texturing, the laser-textured surface shows a contact angle of $0^{\circ}$, indicating the surface becomes superhydrophilic, as shown in Figure $5 \mathrm{~b}$. With the heat treatment, the contact angle of the laser textured Ti surface is increased to $155.0^{\circ} \pm 2.9^{\circ}$, demonstrating that the heat treatment can effectively convert the laser textured Ti surface from superhydrophilicity to superhydrophobicity.

\subsection{Surface Microhardness}

The surface microhardness is measured at five different locations on top of the untreated Ti surface and laser-textured Ti surfaces with different wettabilities, and the average value is reported. It can be seen in Figure 6 that the microhardness of the laser-textured surface is drastically increased compared with that of the untreated surface. In the meantime, the microhardness values for the laser-textured surfaces using different steps size are also quite different, and it is found that the microhardness increases as the step size decreases. This is mainly ascribed to the following reasons: Laser surface texturing can potentially refine the grain. In the meantime, as the texture spacing reduces, the grains become finer and more grain boundaries are generated. Due to the increased number of grain boundaries, dislocations will get stuck at the grain boundary and the microhardness will be distinctly increased [58-60]. This indicates that the laser surface texturing using the 
nanosecond laser pulses can effectively generate microtextures on the surface and enhance the surface functionalities.

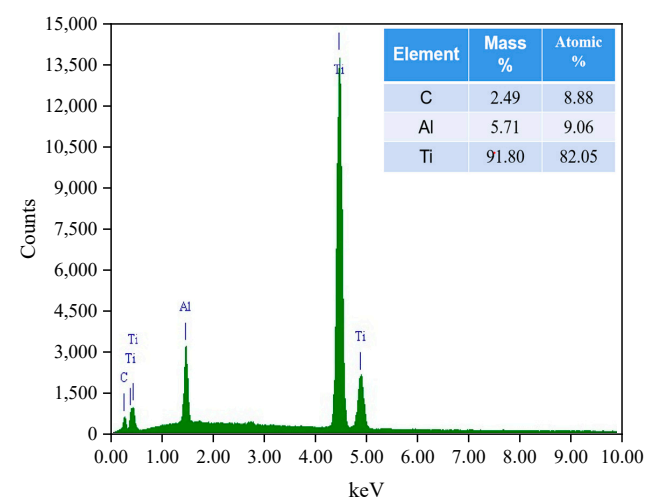

(a)

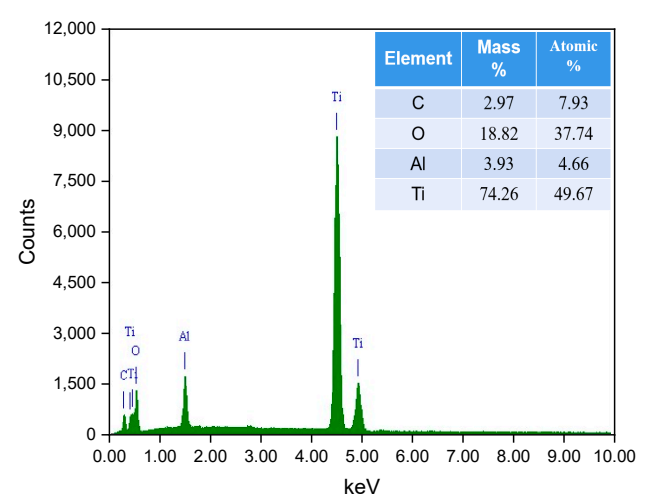

(b)

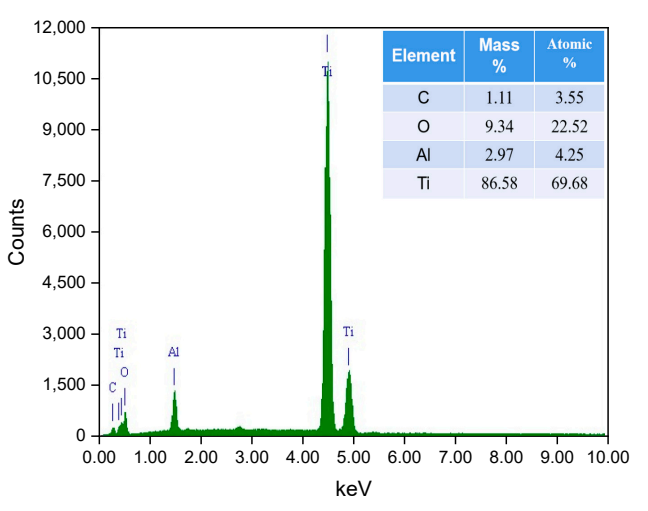

(c)

Figure 4. Comparison of EDS spectrum of samples used in the experiment: (a) is the area 002 in Figure 3b; (b) is the area 001 in Figure 3d; (c) is 001 area in Figure $3 f$.

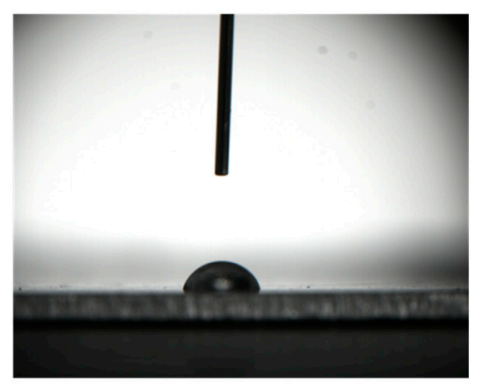

(a)

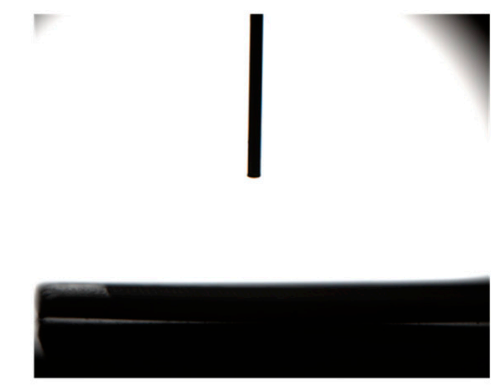

(b)

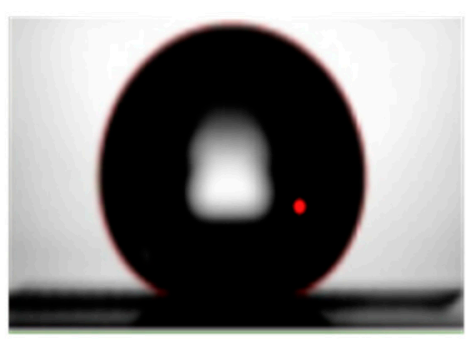

(c)

Figure 5. Diagram of contact angles of different surfaces: (a) untreated surfaces; (b) superhydrophilic surface; (c) superhydrophobic surface. 


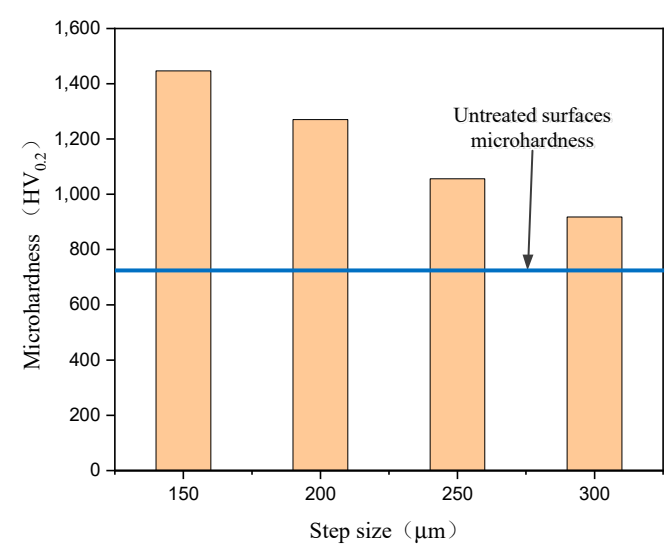

Figure 6. Microhardness of different texture spacing under the load of $1.961 \mathrm{~N}$. (The blue line shows the microhardness of the untreated surface)

\subsection{Erosion Resistance}

The multi-phase flow erosion behavior can be affected by many factors, such as impact angle, the size and of particles, material properties and surface properties [61]. This work mainly focuses on investigating the effect of surface properties on the erosion behavior of laser textured Ti alloy. Figure 7 shows the erosion rates of the untreated surface and laser textured surfaces with different wettabilities using the impact angle of $90^{\circ}$ and the steady flow rate of $10 \mathrm{~m} / \mathrm{s}$. The experimental results indicate that the erosion rate of the untreated surface is $1.75 \times 10^{-7} \mathrm{~g} / \mathrm{g}$ after a $150 \mathrm{~min}$ erosion test. For the laser-textured surfaces with different wettabilities, the erosion rates of the laser-textured superhydrophilic surface are higher than that of the untreated surface, while the erosion rates of the lasertextured superhydrophobic surface are mostly lower than that of the untreated surface. The erosion rates for the laser textured superhydrophobic surfaces using the step sizes of 150,200 and $250 \mu \mathrm{m}$ are $1.16 \times 10^{-7}, 1.33 \times 10^{-7}$ and $1.47 \times 10^{-7} \mathrm{~g} / \mathrm{g}$, respectively, corresponding to an increase of $33.8 \%, 23.8 \%$ and $16.1 \%$ in terms of erosion resistance compare with the untreated surface. When the step size of $300 \mu \mathrm{m}$ is used, the erosion rate reaches $1.97 \times 10^{-7} \mathrm{~g} / \mathrm{g}$, which is relatively higher than but still comparable to that of the untreated surface. From the experimental results, it can be summarized that when the step size used during laser surface texturing is set within a certain range, the corrosion resistance of the laser textured superhydrophobic surface can be well enhanced. The optimal step size turns out to be $150 \mu \mathrm{m}$, which also results from its high hardness induced during the laser texturing process.

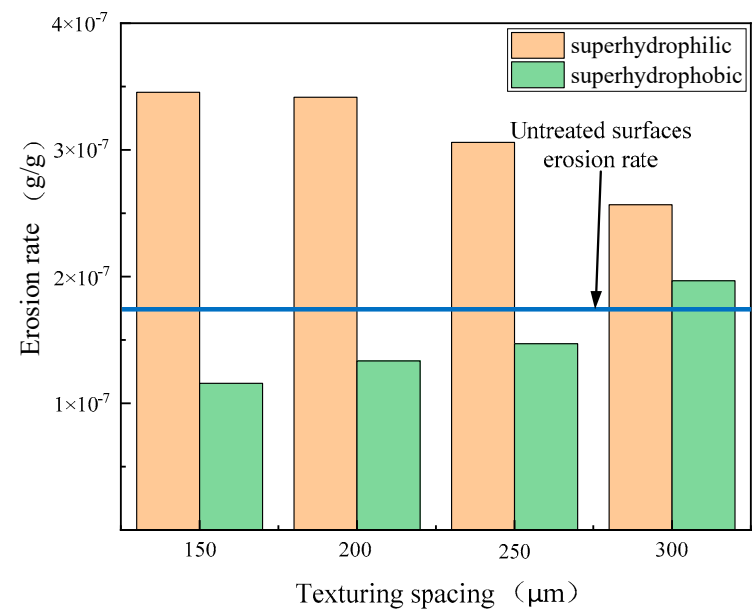

Figure 7. Comparison of erosion rates of titanium alloys with different wettability textures. (The blue line shows the erosion rate of the untreated surface) 


\section{Discussions}

The underlying mechanism for the enhancement of erosion resistance via laser textured superhydrophobic surface will be discussed in detail. After the liquid-solid erosion, the erosion morphology is mainly consisted of three concentric circles, as shown in Figure 8. Previously, Fan et al. [62] and Wang et al. [63] divide the three concentric circles inside the erosion-affected zone into three areas by combining simulation and experimental validation: Zone I is the center zone of erosion; Zone II is the zone close to the center of erosion; Zone III is the zone far away from erosion. The sizes of zones I, II and III are 3, 10 and $18 \mathrm{~mm}$, respectively. They also analyze the erosion mechanisms in these three zones: the erosion in Zone I mainly leads to the formation of impact pits induced by the high-angle and low-speed particles; in Zone II, the erosion is largely caused by the high-speed and low-angle cutting, and also results in the formation of furrowing; and in Zone III, the low-speed and low-angle cutting gives rises to the erosion, and the surface is hit by some rebound particles with low speed and high impact angle, while some impact holes can be observed on the surface. The previous research efforts conclude that the particles in different zones can have very different impact angles and impact speeds.

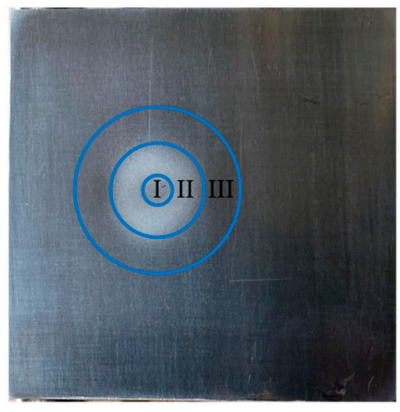

(a)

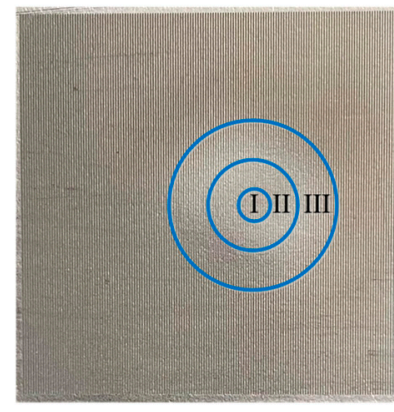

(b)

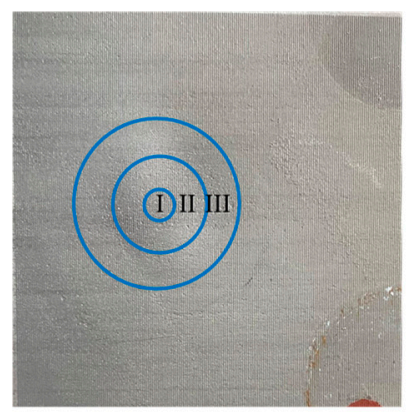

(c)

Figure 8. Schematic diagram of three areas after erosion: (a) untreated surface; (b) superhydrophobic surface; (c) superhydrophilic surface.

To further reveal the effect of laser texturing and surface wettability on the enhancement of the erosion resistance for Ti alloy, the surface morphology of the untreated surface and laser-textured surfaces with different wettabilities after the erosion tests is analyze by SEM, as shown in Figure 9. Figure 9a,d,g shows the surface morphology of Zone I for the untreated surface, laser-textured superhydrophilic surface and laser-textured superhydrophobic surface, respectively. It can be found that the erosion in this area mainly results in the formation of impact pits. Compared with the untreated surface as shown in Figure 3a,c,e, there have appeared a large number of impact pits on the surfaces after the erosion tests. In the meantime, it is also clearly illustrated that the impact pits are relatively larger and denser on the untreated surface compared with those on the laser textured surface, indicating that the laser-induced surface texture can well protect the $\mathrm{Ti}$ alloy surface.

The surface morphology of Zone II for the untreated surface, laser-textured superhydrophilic surface and laser-textured superhydrophobic surface, can be found in Figure $9 b, e, h$, respectively. From these figures, it is shown that the surfaces still suffer from severe erosion induced by particles. However, the erosion-induced damage is relatively slighter compared with that in Zone I. The erosion in this area is mainly caused by cutting and furrowing, and the cutting mark is long. At this moment, the particle energy mainly acts on the horizontal direction. The furrows and cutting marks on the untreated surface are much deeper compared with those on the laser textured surfaces, and the number of these features is also much higher on the untreated surface. In the meantime, partial areas on the laser textured surfaces can be protected by the laser-induced bumps, which are not affected by the erosion process. This further indicates the laser-induced surface texture can 
help to protect the Ti alloy surface. Figure $9 \mathrm{c}, \mathrm{f}, \mathrm{i}$ shows the surface morphology of Zone III for the untreated surface, laser-textured superhydrophilic surface and laser-textured superhydrophobic surface, respectively. The erosion mechanism in this zone is similar to that in Zone II, which is mainly caused by cutting accompanied with a few furrowings. Compared with Zone I and Zone II, the surface damage in Zone III is much lessened, and the degree of damage for the laser textured surface is much reduced compared with that of the untreated surface, which further proves the advantage of laser-induced texture for protecting the Ti alloy surface.

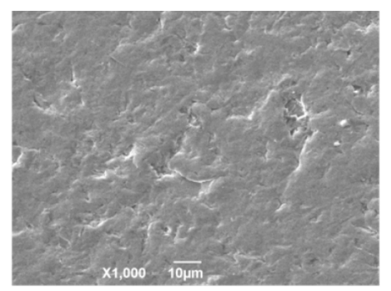

(a) Zone I

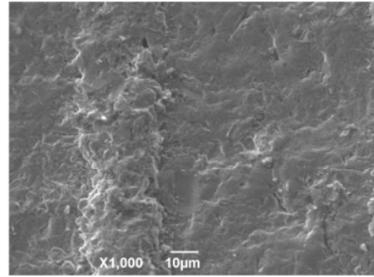

(d) Zone I

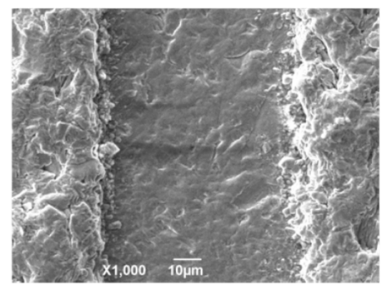

(g) Zone I

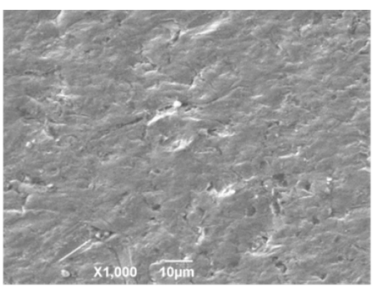

(b) Zone II

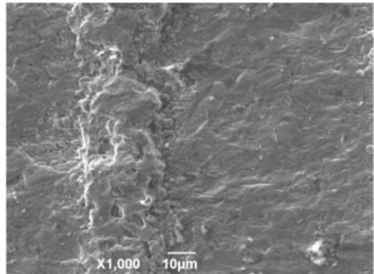

(e) Zone II

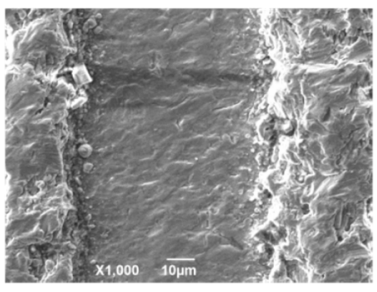

(h) Zone II

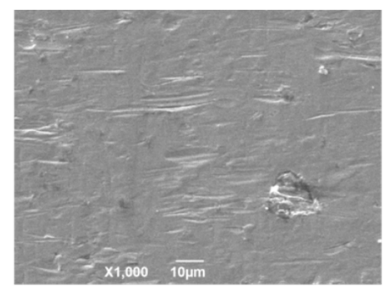

(c) Zone III

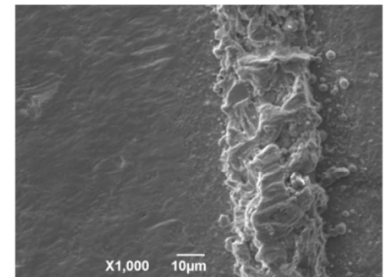

(f) Zone III

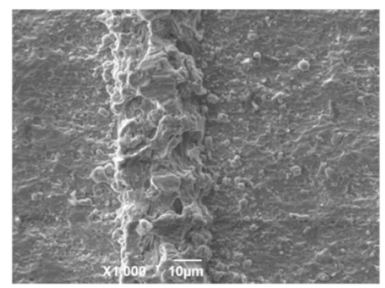

(i) Zone III

Figure 9. Erosion morphology of samples without laser treatment and laser textured samples with different wettabilities: $(\mathbf{a}-\mathbf{c})$ the samples without texturing treatment; $(\mathbf{d}-\mathbf{f})$ superhydrophilic surfaces with texture spacing of $150 \mu \mathrm{m}$, respectively; $(\mathbf{g}-\mathbf{i})$ superhydrophobic surfaces with texture spacing of $150 \mu \mathrm{m}$, respectively.

Meanwhile, it is found in Figure 7 and the erosion rates of laser textured superhydrophilic surface are higher. As shown in Figure $9 \mathrm{~d}-\mathrm{i}$, the laser-induced textures are more severely destructed on the superhydrophilic surface, in which the whole surface is affected by the erosion process, while on the superhydrophobic surface, only the bump structures and the particles on top are scoured, and laser-induced surface textures can be well persevered. It is thus believed that the laser textured superhydrophobic surface can better protect the Ti alloy surface.

Figure 10 shows the EDS maps of the untreated surface, laser-textured superhydrophilic surface and laser-textured superhydrophobic surface after the erosion test of $150 \mathrm{~min}$. It is found that compared with the untreated surface, the Ti element has a lower atomic percentage and the $\mathrm{O}$ and $\mathrm{Si}$ elements have a higher atomic percentage on the superhydrophilic surface. The increase of the $\mathrm{O}$ element is mainly associated with the formation of oxides during the erosion process, and increase of the Si element is caused by the adhesion of broken silica sand debris formed during the impact between silica sand and the surface. The EDS data also show a small amount of $\mathrm{Mg}$ and $\mathrm{Ca}$, which is derived from quartz sand particles. This clearly indicates the chemical reactions occur on the superhydrophilic surface accompanied with the adhesion of silica sand. Due to the 
high water affinity and adhesion of the superhydrophilic surface, the silica sand debris is more likely to adhere to the surface [64]. Even though the microhardness of the superhydrophilic surface is increased, while superhydrophilicity leads to the increase of adhesion force between the liquid-solid two-phase flow and the surface. Here, the adhesion of liquid aggravates the corrosion effect leading to surface oxidation, and the adhesion of solid particles results in weight increase. Therefore, though the increase of microhardness reduces the amount of erosion, the weight increase induced by adhesion dominates and the total erosion rate increases.

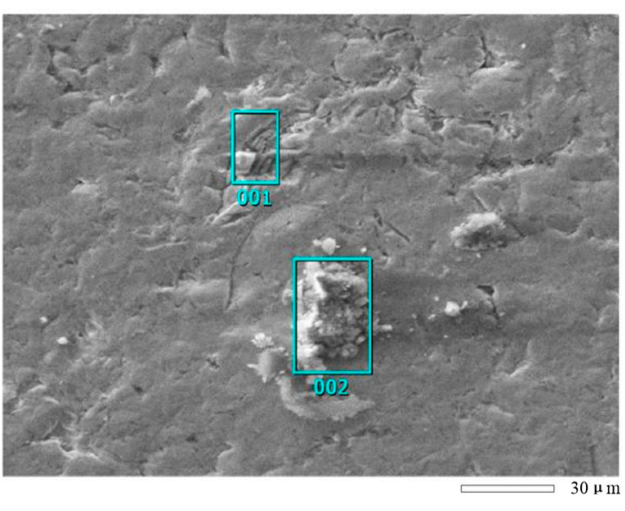

(a)

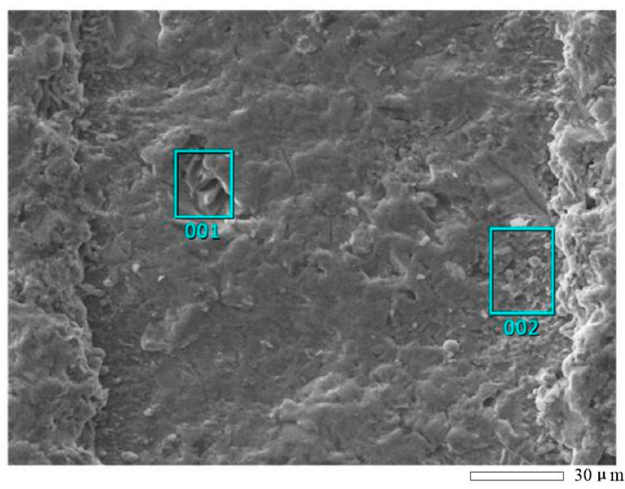

(c)

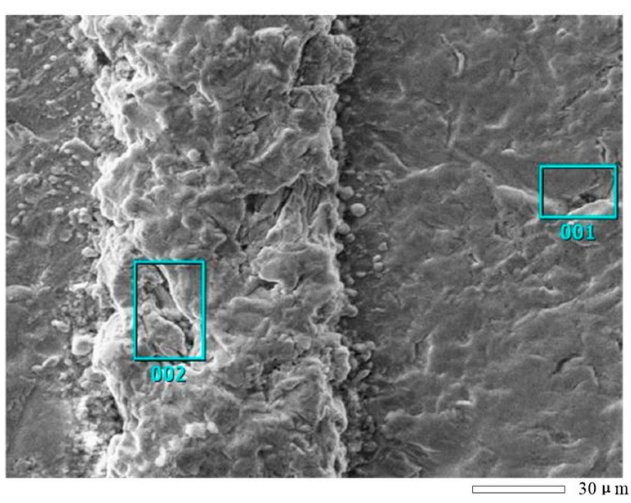

(e)

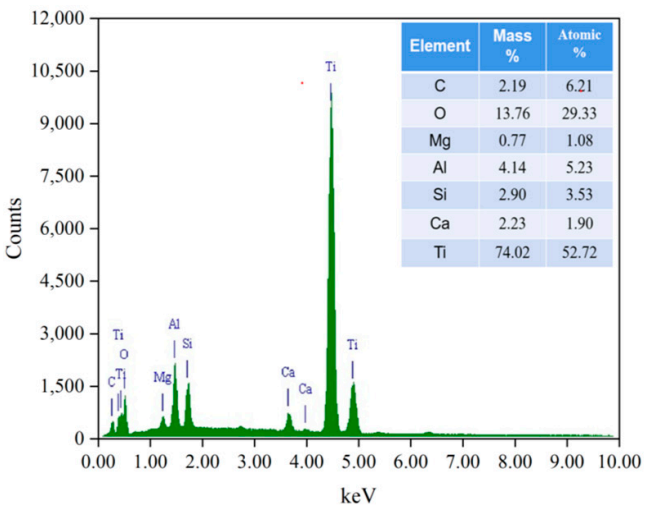

(b)

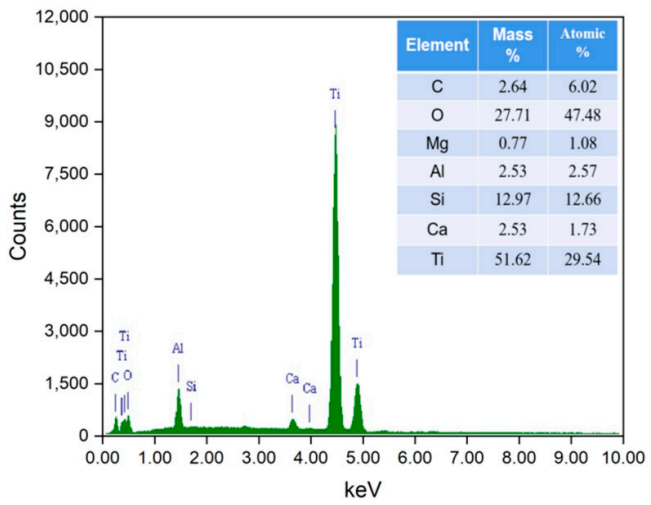

(d)

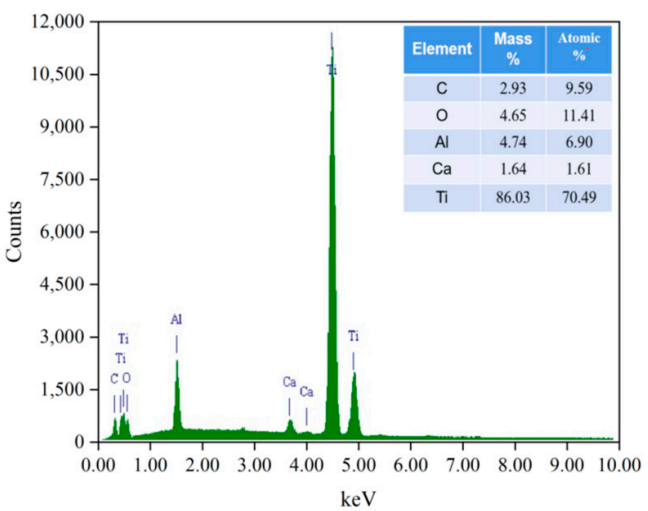

(f)

Figure 10. EDS spectra after erosion: (a) the sample without texture treatment; (c,e) superhydrophilic and superhydrophobic surfaces with texture spacing of $150 \mu \mathrm{m}$, respectively; (b) the spectrum in area 001 of (a); (d) the spectrum in area 001 of (c); (f) area 001 of (e). 
Under the same condition, only $\mathrm{Ti}$ and $\mathrm{Al}$ elements have slight changes on the superhydrophobic surface before and after the erosion test, as shown in Figures $4 \mathrm{c}$ and 10f. This demonstrates the surface chemistry almost remains unchanged on the superhydrophobic surface during the erosion test. The underlying mechanism of the improvement for the erosion resistance of laser textured superhydrophobic surface is schematically illustrated in Figure 11. On the one hand, with the impact angle of $90^{\circ}$, platelets are formed and then they will get peeled off from the surface and resulting the material weight loss. According to the erosion model proposed by Oka [65], at the impact angle of $90^{\circ}$ during the erosion process, the microhardness shows negative correlation with the erosion rate. The higher the microhardness, the better the erosion resistance. In this work, the microhardness of the micro bumps induced by laser surface texturing is increased, while the microhardness of the untreated surface remains the same. The smaller the texture spacing, the larger the laser induced area and the microhardness is also higher. No matter whether the surface is superhydrophilic or superhydrophobic, the microhardness is increased, and thus the texture spacing is the main factor that affects surface microhardness and erosion rate. On the other hand, according to the EDS spectra in Figure 10, the oxidation corrosion rate for superhydrophobic surface is lower than that of the superhydrophilic surface. In the meantime, the adhesion between the solid particles and material surface is reduced for the superhydrophobic surface. Adhesion mainly occurs on the untreated surface area as shown in Figure 11, and as the texture spacing reduces, the untreated area becomes smaller leading to few adhered solid particles.

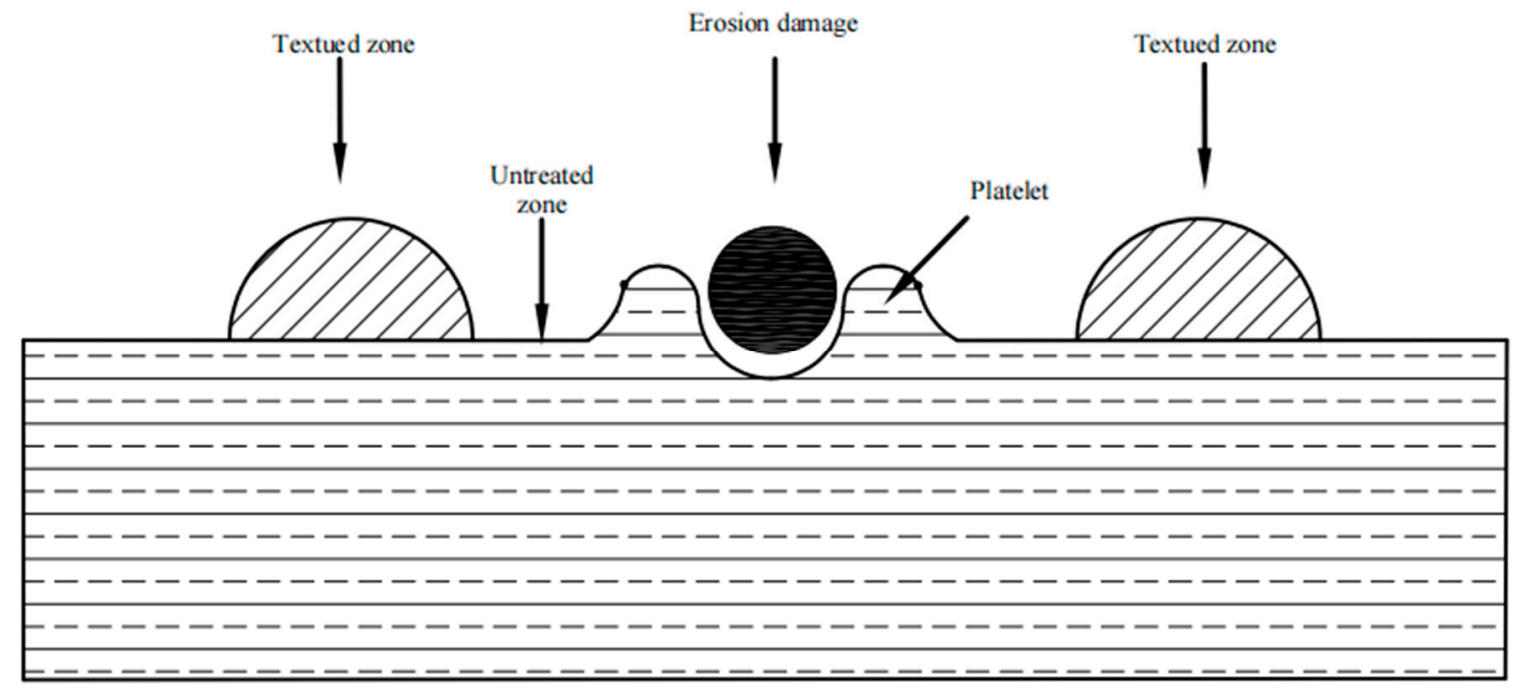

Figure 11. Schematic for underlying mechanism of the improvement for the erosion resistance of laser textured superhydrophobic surface.

However, even though the microhardness of the superhydrophilic surface is increased, while superhydrophilicity leads to the increase of adhesion force between the liquid-solid two-phase flow and the surface. Here, the adhesion of liquid aggravates the corrosion effect leading to surface oxidation, and the adhesion of solid particles results in weight increase. Therefore, though the increase of microhardness reduces the amount of erosion, the weight increase induced by adhesion dominates and the total erosion rate increases for the superhydrophilic surface. To summarize, using the smaller texture spacing, the erosion resistance of the laser textured superhydrophobic Ti alloy surface can be effectively increased.

\section{Conclusions}

In conclusion, this work utilizes the combination of laser texturing and heat treatment to fabricated superwetting (superhydrophilic and superhydrophobic) surfaces with periodic surface structure. Furthermore, the surface microstructure, surface chemistry, surface 
wettability and microhardness are evaluated. Finally, using an in-house built erosion experimental setup, the erosion resistance is evaluated for the untreated surface and the laser textured surfaces with different wettabilities. Some main findings are summarized below.

(1) By laser texturing and heat treatment, Ti-6Al-4V surface with micro-bumps is formed. The contact angle measurements indicate that the untreated surface exhibits a water contact angle of $64.8^{\circ} \pm 2.9^{\circ}$, which is hydrophilic. The laser textured surface has a water contact angle of $0^{\circ}$ exhibiting superhydrophilicity, while the water contact angle is increased to $155.0^{\circ} \pm 2.9^{\circ}$ for the laser textured surface after heat treatment exhibiting superhydrophobicity. The microhardness measurements indicate that the microhardness of the laser textured surfaces is much higher that of the untreated surface.

(2) Through the analysis of the erosion rate for different surfaces, it is experimentally demonstrated that the erosion rates of the laser textured superhydrophobic surfaces with the step sizes of 150, 200 and $250 \mu \mathrm{m}$ are lower than that of the untreated surface. The erosion resistance of the laser textured surface with the step size of $150 \mu \mathrm{m}$ is increased by up to $33.9 \%$ compared with the untreated surface. The superhydrophobic laser textured surface can inhibit oxidation corrosion on the surface, and only very little amount of silica sand adheres to the surface.

(3) The erosion rates of the laser textured superhydrophilic surfaces is higher than that of the untreated surface because amount of silica sand adheres to the surface and result in the weight increase after erosion experiments.

Author Contributions: Conceptualization, Z.W.; Data curation, T.W.; Formal analysis, J.S. and Q.W.; Investigation, J.S.; Methodology, T.W. and H.W.; Project administration, Z.W. and Q.W.; Resources, Z.W. and Q.W. All authors have read and agreed to the published version of the manuscript.

Funding: This research was funded by the National Natural Science Foundation of China (52074220 and 52105175), Basic Research Post-graduate Innovation and Practical Ability Training Plan of Xi'an Shiyou University (YCS21113151) and the Natural Science Foundation of Jiangsu Province (BK20210235).

Institutional Review Board Statement: Not applicable.

Informed Consent Statement: Not applicable.

Data Availability Statement: Data is contained within the article.

Conflicts of Interest: The authors declare no conflict of interest.

\section{References}

1. Katayama, S.; Matsunawa, A.; Morimoto, A.; Ishimoto, S.; Arata, Y. Surface hardening of titanium by laser nitriding. In Proceedings of the ICALEO'83, Los Angeles, CA, USA, 14-17 November 1983; pp. 127-134.

2. Kurc-Lisiecka, A.; Ozgowicz, W.; Ratuszek, W.; Kowalska, J. Analysis of deformation texture in AISI 304 steel sheets. Solid State Phenom. 2013, 203-204, 105-110. [CrossRef]

3. Opiela, M.; Grajcar, A. Hot deformation behavior and softening kinetics of Ti-V-Bmicroalloyed steels. Arch. Civ. Mech. Eng. 2012, 12,327-333. [CrossRef]

4. Qian, J. Application and development of new titanium alloys for aerospace. Chin. J. Rare Met. 2000, 24, $218-223$.

5. Biswas, A.; Li, L.; Maity, T.K.; Chatterjee, U.K. Laser surface treatment of Ti-6Al-4V forbio-implant application. Lasers Eng. 2007, 17, 59-73.

6. Biswas, A.; Li, L.; Chatterjee, U.K.; Manna, I.; Pabi, S.K.; Majumdar, J.D. Mechanical and electrochemical properties of laser surface nitrided Ti-6Al-4V. Scr. Mater. 2008, 59, 239-242. [CrossRef]

7. Man, H.C.; Bai, M.; Cheng, F.T. Laser diffusion nitriding of Ti-6Al-4V for improving hardness and wear resistance. Appl. Surf. Sci. 2011, 258, 436-441. [CrossRef]

8. Majumdar, J.D. Laser gas alloying of Ti-6Al-4V. Phys. Procedia 2011, 12, 472-477. [CrossRef]

9. Liu, Z.G.; Wan, S.; Nguyen, V.B.; Zhang, Y.W. A numerical study on the effect of particle shape on the erosion of ductile materials. Wear 2014, 313, 135-142. [CrossRef]

10. Dong, G.; Zhang, J.Y. Developments of research on the solid particle erosion of materials. J. Mater. Sci. Eng. $2003,21,307-312$.

11. Han, Z.; Yin, W.; Zhang, J.; Jiang, J.; Niu, S.; Ren, L. Erosion-resistant surfaces inspired by tamarisk. J. Bionic Eng. 2013, $10,479-487$. [CrossRef]

12. Huang, H.; Zhang, Y.; Ren, L. Particle erosion resistance of bionic samples inspired from skin structure of desert lizard, Laudakin stoliczkana. J. Bionic Eng. 2012, 9, 465-469. [CrossRef] 
13. Ren, L.Q.; Liang, Y.H. Biological couplings: Function, characteristics and implementation mode. Sci. China Technol. Sci. 2010, 53, 379-387. [CrossRef]

14. Ren, L.Q.; Liang, Y.H. Biological couplings: Classification and characteristic rules. Sci. China Ser. E Technol. Sci. 2009, 52, 2791-2800. [CrossRef]

15. Ren, L.Q. Progress in the bionic study on anti-adhesion and resistance reduction of terrain machines. Sci. China Ser. E Technol. Sci. 2009, 52, 273-284. [CrossRef]

16. Bhushan, B. Biomimetics: Lessons from nature-An overview. Philos. Trans. R. Soc. A Math. Phys. Eng. Sci. 2009, 367, 1445-1486. [CrossRef]

17. Hua, X.; Wang, C.; Hao, J.; Chen, Y.; Xie, X.; Fu, Y. Picosecond laser processing technology of micro-dimple texture on surface of TC11 titanium alloy. Surf. Technol. 2018, 47, 42-47.

18. Wang, M.; Wang, C.; Kang, J.; Zhu, L.; Yue, W.; Fu, Z. Effects of shape parameters of laser surface texture on tribological performance of titanium alloy. China Surf. Eng. 2017, 30, 71-77.

19. Machado, A.R.; da Silva, L.R.R.; De Souza, F.C.R.; Davis, R.; Pereira, L.C.; Sales, W.F.; De Rossi, W.; Ezugwu, E.O. State of the art of tool texturing in machining. J. Mater. Process. Technol. 2021, 293, 117096. [CrossRef]

20. Wang, Y.; Zhang, M.; Li, K.; Hu, J. Study on the surface properties and biocompatibility of nanosecond laser patterned titanium alloy. Opt. Laser Technol. 2021, 139, 106987. [CrossRef]

21. Bulatov, V.P.; Krasny, V.A.; Schneider, Y.G. Basics of machining methods to yield wear- and fretting-resistive surfaces, having regular roughness patterns. Wear 1997, 208, 132-137. [CrossRef]

22. Schneider, Y.G. Formation of surfaces with uniform micropatterns on precision machine and instruments parts. Precis. Eng. 1984, 6, 219-225. [CrossRef]

23. Stephens, L.S.; Siripuram, R.; Hayden, M.; McCartt, B. Deterministic micro asperities on bearings and seals using a modified LIGA process. J. Eng. Gas Turbines Power 2004, 126, 573-580. [CrossRef]

24. Wang, X.; Kato, K. Improving the anti-seizure ability of SiC seal in water with RIE texturing. Tribol. Lett. 2003, 14, 275-280. [CrossRef]

25. Wang, X.; Kato, K.; Adachi, K. The Lubrication Effect of micro-pits on parallel sliding faces of SiC in water. Tribol. Trans. 2002, 45, 294-301. [CrossRef]

26. Wang, X.; Kato, K.; Adachi, K.; Aizawa, K. Loads carrying capacity map for the surface texture design of SiC thrust bearing sliding in water. Tribol. Int. 2003, 36, 189-197. [CrossRef]

27. Uehara, Y.; Wakuda, M.; Yamauchi, Y.; Kanzaki, S.; Sakaguchi, S. Tribological properties of dimpled silicon nitride under oil lubrication. J. Eur. Ceram. Soc. 2004, 24, 369-373. [CrossRef]

28. Etsion, I. Improving tribological performance of mechanical components by laser surface texturing. Tribol. Lett. 2004, 17, 733-737. [CrossRef]

29. Raeymaekers, B.; Etsion, I.; Talke, F.E. Enhancing tribological performance of the magnetic tape/guide interface by laser surface texturing. Tribol. Lett. 2007, 27, 89-95. [CrossRef]

30. Etsion, I.; Halperin, G.; Brizmer, V.; Kligerman, Y. Experimental investigation of laser surface textured parallel thrust bearings. Tribol. Lett. 2004, 17, 295-300. [CrossRef]

31. Etsion, I.; Kligerman, Y.; Halperin, G. Analytical and experimental investigation of laser-textured mechanical seal faces. Tribol. Trans. 1999, 42, 511-516. [CrossRef]

32. Meijer, J. Laser beam machining (LBM), state of the art and new opportunities. J. Mater. Process. Technol. 2004, 149, 2-17. [CrossRef]

33. Geiger, M.; Roth, S.; Becker, W. Influence of laser-produced microstructures on the tribological behaviour of ceramics. Surf. Coat. Technol. 1998, 100, 17-22. [CrossRef]

34. Dausinger, F. Surface structuring of metals with short and ultrashort laser pulses. Proc. SPIE_Int. Soc. Opt. Eng. 2003, 4830, 501-505.

35. Gerbig, Y.; Dumitru, G.; Romano, V.; Haefke, H. Effects of laser texturing on technical surfaces. MRS Online Proc. Libr. Arch. 2002, 750, 537. [CrossRef]

36. Ryk, G.; Kligerman, Y.; Etsion, I. Experimental Investigation of laser surface texturing for reciprocating automotive components. Tribol. Trans. 2002, 45, 444-449. [CrossRef]

37. Liu, Y.; Wen, S. Micro-Fabrication mechanise of excimer laser on various materials. Mech. Sci. Technol. 2005, $24,62-65$.

38. Yang, G.; Li, Y. Research and development status of medical titanium alloys. Foundry Technol. 2016, 37, $2062-2064$.

39. Samanta, A.; Wang, Q.; Shaw, S.K.; Ding, H. Roles of chemistry modification for laser textured metal alloys to achieve extreme surface wetting behaviors. Mater. Des. 2020, 192, 108744. [CrossRef]

40. Hosono, E.; Fujihara, S.; Honma, I.; Zhou, H. Superhydrophobic perpendicular nanopin film by the bottom-up process. J. Am. Chem. Soc. 2005, 127, 13458-13459. [CrossRef]

41. Hosono, E.; Fujihara, S.; Honma, I.; Zhou, H. The fabrication of an upright-standing zinc oxide nanosheet for use in dye-sensitized solar cells. Adv. Mater. 2005, 17, 2091-2094. [CrossRef]

42. Yang, C. Electrochemical method to prepare stable superhydrophobic titanium surface. New Build. Mater. 2016, $43,81-83$.

43. Fürstner, R.; Barthlott, W.; Neinhuis, C.; Walzel, P. Wetting and self-cleaning properties of artificial superhydrophobic surfaces. Langmuir ACS J. Surf. Colloids 2005, 21, 956-961. [CrossRef] 
44. Peng, G.; Zheng, Y.; Wen, M.; Cheng, S.; Lei, J. Icephobic/anti-icing properties of micro/nanostructured surfaces. Adv. Mater. 2012, 24, 2642-2648.

45. Emelyanenko, A.M.; Shagieva, F.M.; Domantovsky, A.G.; Boinovich, L.B. Nanosecond laser micro- and nanotexturing for the design of a superhydrophobic coating robust against long-term contact with water, cavitation, and abrasion. Appl. Surf. Sci. 2015, 332, 513-517. [CrossRef]

46. Li, B.; Li, H.; Huang, L.; Ren, N.; Kong, J. Femtosecond pulsed laser textured titanium surfaces with stable superhydrophilicity and superhydrophobicity. Appl. Surf. Sci. 2016, 389, 585-593. [CrossRef]

47. Xu, J.; Mei, L.; Yan, Z.; Lu, Q. Advance of wetting behavior research on the superhydrophobic surface with micro-and nanostructures. Prog. Chem. 2006, 18, 1425-1433.

48. Fahim, J.; Hadavi, S.M.M.; Ghayour, H.; Hassanzadeh Tabrizi, S.A. Cavitation erosion behavior of super-hydrophobic coatings on Al5083 marine aluminum alloy. Wear 2019, 424, 122-132. [CrossRef]

49. Rius-Ayra, O.; Castellote-Alvarez, R.; Escobar, A.M.; Llorca, I.N. Superhydrophobic coating bioinspired on rice leaf: A first attempt to enhance erosion resistance properties at environmental conditions with ceramic particles. Mater. Sci. Forum 2018, 941, 1874-1879. [CrossRef]

50. Del Cerro, A.D.; Römer, G.R.B.E.; Huis, A.J. Erosion resistant anti-ice surfaces generated by ultra short laser pulses. Phys. Procedia 2010, 5, 231-235. [CrossRef]

51. Siddiqui, A.A.; Dubey, A.K.; Paul, C.P. A study of metallurgy and erosion in laser surface alloying of AlxCu0.5FeNiTi high entropy alloy. Surf. Coat. Technol. 2019, 361, 27-34. [CrossRef]

52. Wahab, J.A.; Ghazali, M.J. Erosion resistance of laser textured plasma-sprayed $\mathrm{Al}_{2} \mathrm{O}_{3}-13 \% \mathrm{TiO}_{2}$ coatings on mild steel. Wear 2019, 432, 202937. [CrossRef]

53. Yu, W.; Lei, Y. Microstructure and erosion performance of laser remelting Fe-Cr coating on 304 stainless steel. Appl. Laser 2020, 40, 795-799.

54. Wang, X. Erosion Mechanism Research of Micro-Nanostructure Hydrophobic Titanium Alloy; Shanghai Jiao Tong University: Shanghai, China, 2017.

55. Jing, L.I.; Zhao, S.C.; Feng, D.U.; Fan, F.Y.; Pan, L.D.; Hua-Dong, Y. Fabrication of groove and grid structure surface with superhydrophobicity and corrosion resistance by laser. J. Mater. Eng. 2018, 46, 86-91.

56. Qian, Y.; Jiang, M.; Zhang, Z.; Huang, H.; Yan, J. On the transformation between micro-concave and micro-convex in nanosecond laser ablation of a Zr-based metallic glass. J. Manuf. Process. 2021, 68, 1114-1122. [CrossRef]

57. Wang, H. Nanosecond Laser Polishing Titanium Alloy Ti6Al4V Mechanism and Experimental Study; Hubei University of Technology: Wuhan, China, 2020.

58. Pan, X.; Wang, X.; Tian, Z.; He, W.; Shi, X.; Chen, P.; Zhou, L. Effect of dynamic recrystallization on texture orientation and grain refinement of Ti6Al4V titanium alloy subjected to laser shock peening. J. Alloys Compd. 2021, 850, 156672. [CrossRef]

59. Gao, Y.; Yang, P.; Yuanyuan, D.U.; Chen, X.; Goldamp, S.J. Hardening mechanism and vickers-hardness test of solid gold jewelry. Precious Met. 2018, 39, 177-184.

60. Zhang, J.; Liu, Y.; Bayat, M.; Tan, Q.; Yin, Y.; Fan, Z.; Liu, S.; Hattel, J.H.; Dargusch, M.; Zhang, M.X. Achieving high ductility in a selectively laser melted commercial pure-titanium via in-situ grain refinement. Scr. Mater. 2021, 191, 155-160. [CrossRef]

61. Oka, Y.I.; Mihara, S.; Yoshida, T. Impact-angle dependence and estimation of erosion damage to ceramic materials caused by solid particle impact. Wear 2009, 267, 129-135. [CrossRef]

62. Fan, X.; Liu, W.; Zhu, Y.; Cai, F.; Yu, Y.; Sun, W.; Li, X. Influence of impingement velocity on $\mathrm{CO}_{2}$ erosion-corrosion behaviour of X70 steel at high-temperature and high-pressure conditions. Surf. Technol. 2020, 49, 296-304.

63. Wang, Z.; Qu, H.; Dou, Y.; Wang, W.; Cao, K. Comparison of abrasive jet erosion behavior in water and non-newtonian hydroxypropylguar gum solution. Surf. Technol. 2021, 50, 160-167.

64. Li, H.; Yu, S.; Hu, J.; Yin, X. Modifier-free fabrication of durable superhydrophobic electrodeposited Cu-Zn coating on steel substrate with self-cleaning, anti-corrosion and anti-scaling properties. Appl. Surf. Sci. 2019, 481, 872-882. [CrossRef]

65. Oka, Y.I.; Okamura, K.; Yoshida, T. Practical estimation of erosion damage caused by solid particle impact. Wear 2005, 259 , 95-101. [CrossRef] 